\title{
A Corpus-Assisted Translation Study of Strategies Used in Rendering Culture-Bound Expressions in the Speeches of King Abdullah II
}

\author{
Leen Al-Khalafat \\ Department of English Language and Translation, Applied Science Private University, Amman, Jordan \\ Ahmad S. Haider \\ Department of English Language and Translation, Applied Science Private University, Amman, Jordan
}

\begin{abstract}
Translation is defined as transferring meaning and style from one language to another, taking the text producer's intended purpose and the audience culture into account. This paper uses a 256,000-word Arabic-English parallel corpus of the speeches of King Abdullah II of Jordan from 1999 to 2015 to examine how some culture-bound expressions were translated from Arabic into English. To do so, two software packages were used, namely Wordsmith 6 and SketchEngine. Comparing the size of the Arabic corpus with its English counterpart using the wordlist tool of WS6, the researchers found that the number of words (tokens) in the English translation is more than the Arabic source text. However, the results showed that the Arabic language has more unique words, which means that it has more lexical density than its English counterpart. The researchers carried out a keyword analysis and compared the Arabic corpus with the ArTenTen corpus to identify the words that King Abdullah II saliently used in his speeches. Most of the keywords were culturebound and related to the Jordanian context, which might be challenging to render. Using the parallel concordance tool and comparing the Arabic text with its English translation showed that the translator/s mainly resorted to the strategies of deletion, addition, substitution, and transliteration. The researchers recommend that further studies be conducted using the same approach but on larger corpora of other genres, such as legal, religious, press, and scientific texts.
\end{abstract}

Index Terms-Arabic, English, translation, parallel corpus, translation strategies

\section{INTRODUCTION}

Translation is a complicated activity in which translators are supposed to transfer the text's linguistic and stylistic components and convey the text's cultural and ideological aspects. Toury (1995, p. 200)_defined translation as "a kind of activity which inevitably involves at least two languages and two cultural traditions." Nida and Taber (1982, p. 12) stated that "translation consists in reproducing in the receptor language the closest natural equivalent of the source language message, first in terms of meaning and secondly in terms of style." The present study is concerned with the translation strategies used by interpreters and translators in rendering some culture-bound expressions from Arabic and English. In this study, the researchers use an Arabic-English parallel corpus of the speeches of King Abdullah II to examine how some salient words were translated from Arabic into English.

Political speech can be used to comprise many forms ranging from negotiations within formal meetings to briefings, interviews, press conferences, etc. Political speeches are considered historically and culturally rooted. Each speech has a particular function to fulfill, depending on the ongoing political activity taking place at a given moment (Haider, 2019b) In definition, political speech refers to a statement or a comment that is made about the government's actions, private or individual actions. As the political system consists of strongly linked texts, the translator must adhere to the source text's coherence with other related political texts. Political translation, often overlooked in the field of politics, represents a form of political activity, and this is why it should be given more importance and treated with a kind of caution.

Any problem in translating political texts in general and presidential and royal speeches, in particular, may lead to conflicts and disputes between countries and nations. This puts pressure on translators and interpreters, especially when the two involved parties have different cultural and political perspectives. Since the focus of this study is on Jordan, which is located in a heated area in the Middle East being surrounded by areas of conflicts as it has borders with occupied Palestine, Iraq, and Syria, it is evident that the speeches delivered by King Abdullah II are important because they are accessible by lots of people locally, regionally, and internationally. This is why having valid translations for these speeches is crucial, bearing in mind the vital role Jordan plays in the peace process in the Middle East.

In this study, the researchers follow a corpus-assisted approach to investigate the strategies used in translating King Abdullah's speeches from Arabic into English. It is worth noting that various studies have investigated how political texts are translated into different languages and examined what translation strategies are used in rendering these texts 
(see Abdi \& Satariyan, 2020; Afzali, 2013; Davaninezhad, 2016; Sárosi-Márdirosz, 2014; Schäffner, 2004, 2008). However, to the best of the researchers' knowledge, only a few have been carried out using corpus-assisted methods on Arabic-English political texts. Accordingly, using corpus techniques in investigating a corpus of Arabic-English political speeches is the gap that this study fills. This study aims to answer the following question:

Using a corpus-assisted approach, what are the main strategies used in translating culture-related terms in King Abdullah's Arabic speeches into English?

\section{LITERATURE REVIEW}

\section{A. Translating Political Texts}

As it is the case of translating texts from various genres, including press, legal, medical, and others, translating political texts is of great importance. The translation of political texts has been the subject of different research studies. It plays a crucial role in the development of political discourse, political ideas, beliefs, and practices of a society or some part of it (Schäffner, 2004). Having political texts in different languages is crucial as it helps people of other nations better understand the various strategies and policies, economy, diplomacy, culture, etc.

Translating political texts has been a challenging process that few people worldwide have mastered well. Some restrictions and rules need to be followed while translating political texts. Political translations have been critical and vital as they are part of international negotiations, power games, and political struggles (Bánhegyi, 2014). Therefore, multidimensional issues should be considered in the context of political translation contexts.

An essential notion in translation is equivalence. Nida's theory is one of the most notable works which categorized equivalence into two types, namely formal and dynamic. Formal equivalence is seen to be faithful to the source text's form and style, whereas dynamic equivalence tends to reflect the essence and gist of the source text. In the process of translation, translators and interpreters may follow different translation methods. A translation method is defined as the way that translators and interpreters adopt in transferring meaning from one language (the source language) into another (the target language). Newmark (1988) stated that the translation method could be literal or free. The literal translation (word-for-word) means being highly close to the meaning, grammar, and structure of the source text. In contrast, free translation means transferring the connotative meaning from one language to another (sense-for-sense). Each of the two methods, i.e., literal and free, has advantages and disadvantages based on whether the translator/interpreter is biased towards the source language or the target language.

Arabic and English belong to different language families, where the former is Semitic, while the latter is IndoEuropean. The two languages have different features and characteristics. For example, 'repetition' and emotiveness' are used more often in Arabic than English and more in speaking than in writing. In translating Arabic political texts into English, investigating the political, social, and cultural contexts of the source and target communities is one of the vital points translators should consider when translating political texts. Translating some political expressions may vary from one context to another, so the task of translators is to provide the proper meaning and make it comprehensible to the audience of the target language. Forms, styles, and meanings should be taken into consideration while translating political discourse. In addition, lexical relations and figurative language, such as hyperbole, exaggeration, and metaphors, should be rendered in acceptable forms in the target language.

\section{B. Translation Strategies}

As there is a variety in the methods of translation, there are different strategies to be followed by translators. The term 'translation strategies' is frequently used in the context of translation studies. Translators need to follow a strategy when they face a problem while translating specific text (Debbas \& Haider, 2020). Baker (2018) suggested some translation strategies to deal with the challenges that may arise while translating a text from one language into another:

1. Using general words: It is a strategy that can be used when the translator cannot find an equivalent in the target language. It consists of changing the semantic level of the problematic expression and using a more general word to express the target text's context. Baker believes that this strategy can be followed in almost all languages. An example of this strategy is translating the Arabic verb "يصلي into the English verb "worship."

2. Using neutral words: this strategy means using less expressive words in the target text. It can be followed when the translator wants to be objective. An example of this strategy is the Arabic word "مhich is translated into the English less expressive equivalent "passed away. "

3. Cultural substitution: translators use this strategy to replace a word in the source text with a suitable word in the target language, considering its cultural effects on the target audience. The aim of using this strategy is to make the target text seem natural to the target reader. An example of this strategy is the Arabic terms

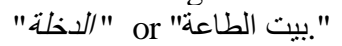

4. Loan words (with explanation): this is another strategy that is required when the translator deals with cultural or new expressions. This strategy is very effective if the word occurs many times in the text. The translator should explain the loan word the first time it appears in the text. An example of this strategy is the Arabic word " ركاة"wich is translated in English into "Zakat (one of Islam pillars)." 
5. Paraphrasing using related words: translators follow this strategy when a word in the source language exists in the target language but in a different form. An example of this strategy is the English source sentence: "The rich and creamy KOLESTRAL-SUPER is easy to apply" which is translated into Arabic as "كولسترال سوبر غني و بشبه الكربيا و سكل الاستخدام."

6. Paraphrasing using unrelated words: this strategy is used when the translators want to simplify a complicated word in the source language which is unknown in the target language using other words with the same meaning. For example, the word "affidavit" is translated into Arabic as " إفادة خطية.

7. Omission: this strategy is beneficial when the translators want to shorten the sentences or avoid repeating some unnecessary words. The meaning should not be clear after omitting the words. An example of it is the source Arabic word "فخامة الرئيس"which translated into English in some contexts "president."

8. Illustration: This strategy is used when the TT equivalent is not enough in rendering the meaning of the ST concept. Translators in this strategy explain the concept briefly. An example of this strategy is: tagged teabags.

Knowing when and how to use these techniques is the aim of Baker's translation strategies list. Each translator can decide which strategy helshe needs depending on the context.

\section{Corpus Linguistics and Translation Studies}

Corpus is defined as a set of language data that is made usable by computers (Hunston, 2002). Corpus Linguistics is "the study of language based on examples of 'real-life' language use" (McEnery \& Wilson, 2001, p. 1). Corpus linguistic software packages and techniques are widely utilized to investigate several linguistic and social phenomena (see AlAbbas \& Haider, 2020; Haider, 2019a; Haider \& Hussein, 2020; Haider \& Olimy, 2019). According to Taylor (2008), it is a methodology rather than a theory of language. Corpus linguistic techniques are widely used in investigating several linguistic phenomena and disciplines, including translation, discourse, lexicology, lexicography, grammar, to mention a few. The techniques that are common in corpus linguistics are dispersion, frequency, collocation, concordance, and keyword. Parallel concordance displays information in the source and target texts in an organized way and shows the words and meanings in their contexts.

There are many types of corpora, such as general corpora, which include huge numbers of texts up to millions of words in different contexts. Another type is specialized corpora which include texts about a particular topic. This type is useful when the users want to investigate a specific topic or phenomenon. A third type is monitor corpora which enable users to update and add texts to the corpus. Fourth, comparable corpora consist of texts in different languages with the same or similar compilations. Another type of multilingual corpora is parallel corpora which contain the same texts in different languages. In this case, the sentences in a particular language are aligned with their counterparts in the other language. Using corpus linguistic software packages and when searching for a particular term, they will automatically get the sentences where the term is mentioned in the source, and the target language, i.e., the mentions will be displayed together in both languages. Users can then observe how the selected word or phrase is translated. For this study, a parallel corpus comprising King Abdullah II Arabic speeches with their English translations is compiled to answer the two research questions mentioned above.

The corpus approaches to translation can help analyze the connotative and denotative meaning of the word. Parallel corpora, which include the texts along with their translations, are beneficial and of great importance for translators and linguists. Baker (2018) is among the leading scholars to explore the use of a corpus-assisted approach in translation. This approach frees translators from the pressure of being biased. It is a matter of fact that there are several approaches used to examine translations of different languages. However, corpus increases the validity of the results. The corpusbased method tells how the word is used in its original/ source and translated/ target texts and the contextual information related to it.

Computer-based research analyses the data in several ways, and the results are accurate, reliable, and fast. There are systemized steps to follow. A corpus-assisted approach for translation is exceptionally beneficial because it works on transcriptions and the translation process (Dazdarevic, Zoranic, \& Fijuljanin, 2015). In the broader sense, in some situations, it is required to translate words in their contexts. The corpus-assisted translation approach involves many disciplines such as semantics, natural language processing, grammar, and lexicography, among others. Further, it is accurate as it depends on algorithms that calculate the frequency of words that can be used to give the most common uses and meanings of the words.

Though the corpus-based approach was introduced a long time ago, it is still not frequently used. This could be due to the unfamiliarity of some scholars with the use of computers in language studies, the misconception of corpus linguistics, and the lack of already compiled parallel corpora in different languages. This type of corpora, i.e., parallel, is the most useful for conducting translation studies, where the same text is available in two or more languages, as the next section shows.

\section{Empirical Studies}

Different studies have investigated the translation of political texts and highlighted the problems the translators encounter and the strategies they resorted to. For example, Munday (2007) analyzed the relationship between ideology and language and how they are related to power through translation studies. The researcher argued that translating political speeches and ideas of other individuals is complicated due to the ideological dynamics that exist in political 
texts. The researcher stated that sensitive texts or speeches cannot be translated explicitly as political discourse in a lot of cases includes different kinds of expressions or terms that can be understood and interpreted differently by people from diverse social and cultural backgrounds due to the difference in the source of the speech on the one hand and the origin of people on another. The difference can also arise in the interpretation of various translators. Al-Hamad (2013) examined political speeches and texts along with their translations and found that the Arabic translations were characterized by symbolism and enthusiasm to draw the attention of the crowd and manipulate them emotionally. Besides, the researcher noticed that synonyms and repetition are highly used, highlighting that the linguistic features of languages and cultures are different. Sárosi-Márdirosz (2014) examined the challenges related to the translation of political texts from English into Hungarian and Romanian. The findings showed that there are no instructions to translate a political speech and that knowing cultural, historical, and political circumstances is part of the translation process. The study concluded that to reach the desired target audience, the political expression should be phrased in a very personalized way.

Various studies examined the translation of presidential and royal speeches. For example, Al-Hammad (1999) highlighted some of the linguistic features in the political discourse by analyzing Jamal Abd El-Nasser's speeches, the late Egyptian president. The researcher divided his results into different categories based on the structural and linguistic aspects, pointing out that Nasser used various clauses, phrases, and even repeated words to emphasize a specific point. Moreover, Nasser sometimes also used religious quotations and poetry in his speeches. Having these features makes the process of translating these speeches into other languages more difficult. Shunnaq (2000) analyzed repeated, and expressive phrases and other characteristics such as hyperbole, humor, and metaphors in the Arabic-English translated speeches of Gamal Abdul Nasser. Twenty relevant excerpts of Nasser's speeches were studied. The researcher suggested that political translators should take into consideration semantic phenomena and be aware that in Arabic, functional repetition and emotional expression can be excessive and tautological in Arabic.

Al-Zu'bi (2000) examined the problems that MA candidates face while translating the terms used by King Abdullah II. The author prepared a translation test and asked 40 students from two Jordanian universities to translate it. Analyzing the translations, the researcher observed that the students lack knowledge of political terms and usually use literal translation. The researcher emphasized the importance of being mindful of the TL (target language) and the SL (source language) along with the cultural, social, and linguistic variations between them. The researcher also pointed out that the first step towards achieving appropriate and effective translation is having translators who are aware of the different features and characteristics of all kinds of political discourse. Mehawesh (2016) explored the figures of speech, mainly metaphor and simile, in the translation of King Abdullah II Political Speeches bearing in mind the persuasive effect they have on the audience, and so should be integrated into the target texts. The researcher examined two methods in dealing with the selected examples; a descriptive method and a comparative method. The findings indicated that to evoke the TL audience's emotions towards the subject, similes and metaphors in the TL text should be produced emotionally. Ayasrah (2017) explored the difficulties of interpreting metaphors in King Abdullah II's political speeches. The researcher used a translation test that included nine items and performed open-ended interviews to address the research goals. Twenty-two students from the MA level were asked to translate the metaphors used in the exam. After that, three translation experts were interviewed to state the aims of the metaphors used in the test. The results showed that interpreters and translators can define the aims of using metaphors by their kinds and the context. MA students strongly followed free translation and word-for-word strategies. Paraphrasing and deletion were sometimes used. The study also found that in translating metaphors, MA students faced serious difficulties, including the inability to decide the acceptable translation strategies, the confusion of the intention and context of the speaker, absence of culture, the inability of expressing emotiveness sense in metaphors, using inappropriate connotation, and the inability to deal with figurative language.

Munday (1998) combined cultural studies, reception theory, functional linguistics, and corpus linguistics to analyze a parallel corpus of the Spanish short stories written by Gabriel Garcia Marquez and their translations into English. The information obtained from this comparison suggested that the initial criterion of the translator choice was concerned mainly with acceptability. Similarly, Kenny (1999) examined the creativity and lexical norms in about a two millionword parallel corpus of modern German literary texts and their translations into English. The author found that normalization is a trend that seemed to constantly appear when facing lexical problems. Alansary, Nagi, and Adly (2007) discussed the idea of building an international Arabic corpus and focused on the step of compiling the data. The researchers discussed three main areas; first, one involves elements of a corpus-based approach, which depends on some factors, including semantics, natural language processing, grammar, and lexicography. The second area shows how the Arabic language needs linguistic tools such as corpus analysis software and how this shortage influences the use of corpus-assisted corpus studies. The third area focuses on the technical layout of the International Corpus of Arabic, including the use of the Arabic language worldwide.

\section{METHODOLOGY}

This section discusses the research method and design of this study. It provides some information about the data source and corpus size, software packages that are used in analyzing the data, corpus linguistic techniques, and the stages to be followed in this study. 


\section{A. Data Source and Corpus Size}

This study uses a 256,000-word Arabic-English parallel corpus of the speeches of King Abdullah II of Jordan from 1999 to 2015. The focus of this study is on the speeches that were delivered in Arabic and translated into English. The corpus contains texts that were collected from King Abdulla's book, speeches, interviews, and letters that were originally retrieved from his official website http://www.kingabdullah.jo/; a website that has considerable information about Jordan and King Abdullah II (Al-Sayed Ahmad, Hammo, \& Yagi, 2017). It is worth noting that the translation is done by interpreters and translators who are affiliated with the Jordanian Royal Court.

After downloading the speeches from the website of King Abdullah II, they were saved as .txt files, i.e., in a form that is readable by corpus linguistic software. After that, the texts were segmented into sentences, and then the Arabic sentences were aligned with their English counterparts, as Figure 1 shows.

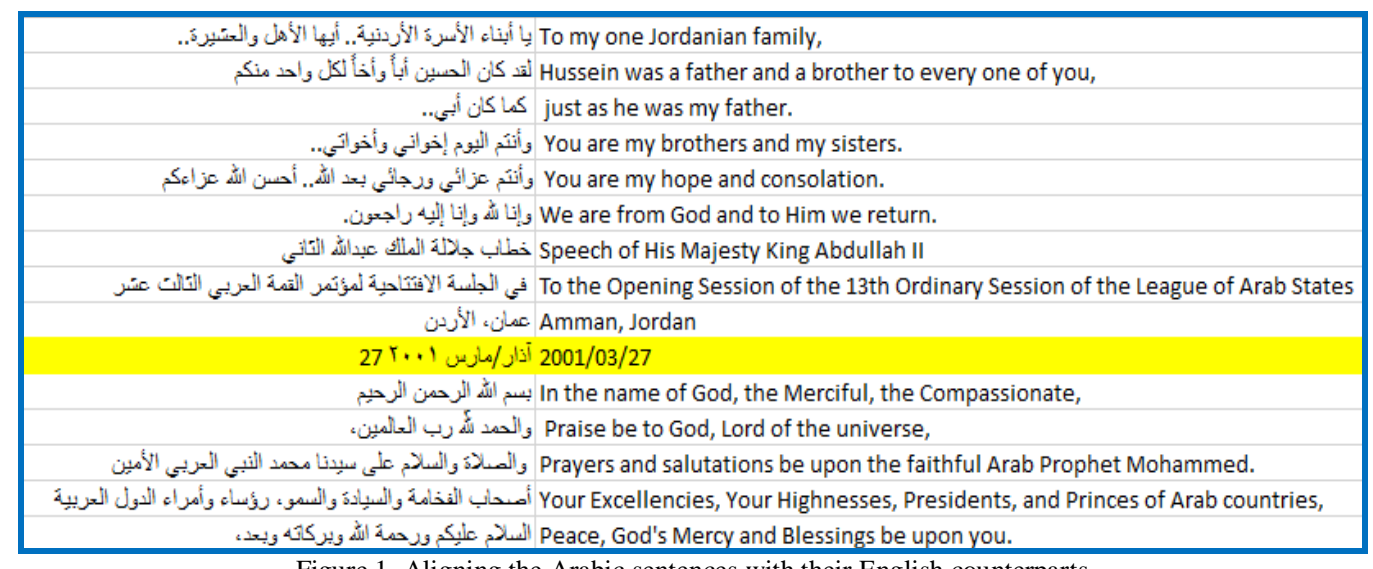

Figure 1. Aligning the Arabic sentences with their English counterparts

\section{B. Software Packages and Techniques to Be Used}

In this study, two software packages are used, namely Wordsmith 6 (Scott, 2012) and SketchEngine (Kilgarriff et al., 2014). Wordsmith 6 (WS6) is a software package developed by the British linguist Mike Scott at the University of Liverpool and is mainly used for corpus linguistic analysis. The software offers different functions, including frequency (wordlist), dispersion, collocation, clusters, concordance, and keyword. For this research, WS6 is used to give statistics for the source Arabic speeches of King Abdullah and their translation in English.

Sketch Engine is a web-based corpus processor for text analysis developed by Adam Kilgarriff. It aims to encourage individuals to research language behavior. SketchEngine provides researchers with access to different corpora in different languages, including the British National Corpus (BNC). In this study, SketchEngine is used to generate parallel concordance, i.e., the concordance lines that include the search term appear in Arabic and English. It is also used to conduct a keyword analysis by comparing the Arabic source with a reference/general Arabic corpus. The keyword list will ease the process of finding out salient words and selecting the words to be investigated further.

There are different corpus-linguistic techniques researchers can use to analyze corpora. These include frequency, clusters, concordance, collocation, and keywords. Baker (2004) argued that keyword and frequency share the same task, but keyword is more complicated. According to Scott (1999), there are three functions of keywords, namely, 'aboutness,' which explains what the corpus is about; second, keywords that determine the style of the corpus, and keywords that are related to proper nouns.

Parallel concordance is used if the corpus under study is parallel. It is used to compare the source text with its translation. Figure (2) shows the parallel concordance of the word $\dot{\gamma}^{\prime}$ and its counterparts in the target text. This helps translators identify translation strategies used in rendering texts. 


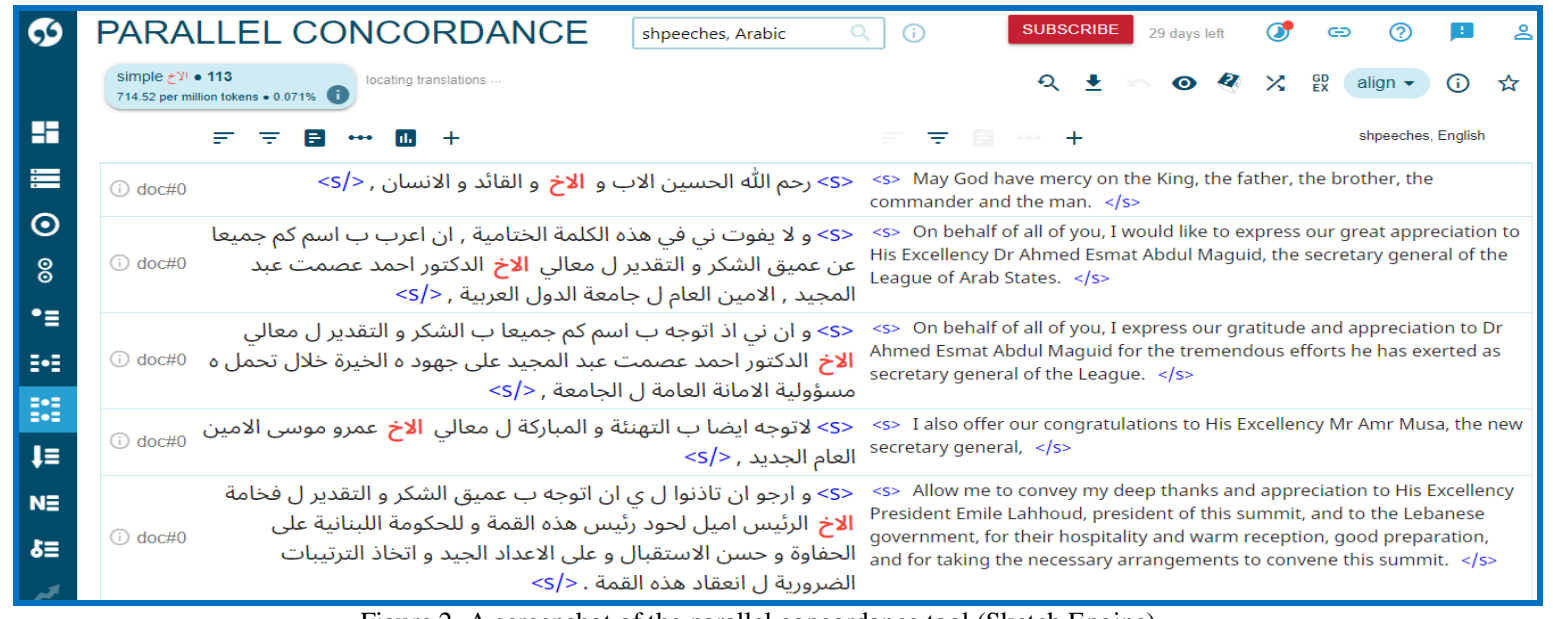

Figure 2. A screenshot of the parallel concordance tool (Sketch Engine)

\section{Procedures of the Study}

In this study, the researchers followed the research process outlined below.

Step1: Preparing the study questions.

Step2: Compiling a parallel corpus that contains King Abdullah II's speeches.

Step 3: Carrying a keyword analysis by comparing the Arabic corpus with the Arabic translation of the English corpus.

Step 4: Selecting some of the most salient words created in step 3.

Step 5: Conducting a parallel concordance for the words selected in step 4.

Step 6: Identifying the translation strategies and linking them to the existing literature.

\section{RESULTS AND DiSCUSSION}

In this section, the researchers analyze the corpus by conducting keyword analysis for the Arabic source corpus and English target corpus. In addition, the strategies used to translate King Abdullah II's speeches from Arabic into English.

\section{A. Statistical Information}

In order to identify the actual size of the Arabic and English corpora, the researchers carried a frequency analysis using WS6. The wordlist tool in WS6 enables researchers to know the number of tokens and types. Token in corpus linguistics is defined as the actual number of all words that appear in the corpus regardless of how many times they are repeated. Type, on the other hand, refers to the unique words that occur in the corpus. For example, a sentence like "Ali is the best brother in the world" consists of 8 tokens and 7 types. Type token ratio (TTR) is the overall number of distinct words (types) divided by the number of all words in the corpus (tokens). The purpose of using TRR is to determine the text's lexical density, which can reveal some information about the features of the text under study.

Arabic Source Text vs. English Target Text

In this section, the researchers compare the size of the Arabic corpus (the Source text corpus) with its English counterpart (the Target text corpus). To do so, Wordsmith 6 software is used, as Figures 3 and 4 show.

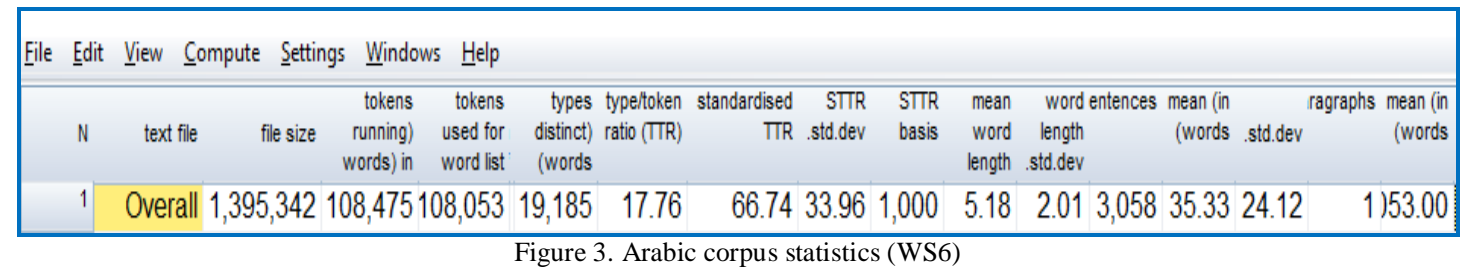

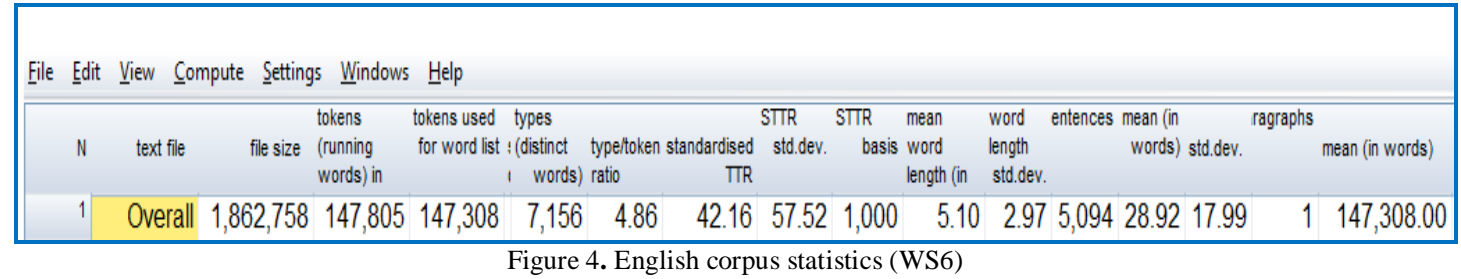

Figures 3 and 4 show some statistics related to the source corpus (Arabic) and the target one (English). The results are summarized in Table 1 . 
TABLE 1

TYPES AND TOKENS IN THE INVESTIGATED CORPORA

\begin{tabular}{|c|c|c|}
\hline Criterion & Arabic corpus & English corpus \\
\hline Tokens & 108,475 & 147,308 \\
\hline Types & 19,185 & 7,156 \\
\hline Type tokens ratio & 17,76 & 4,86 \\
\hline Standardized TTR & 66.74 & 42.16 \\
\hline
\end{tabular}

Table (1) shows the size of the Arabic corpus is 108,475 words (tokens), while the English corpus contains 147,308 words. This shows that the English translation is larger than the Arabic source text. The Arabic corpus has 19185 distinct words (types), while its English counterpart has 7,156 types. It can be noticed that the Arabic language has more unique words, which means that it has more lexical density. However, tokens in the English corpus are more than the Arabic one, indicating the feature of explicitation. According to Vinay and Darbelnet (1995), explicitation is a translation strategy in which meanings are clarified explicitly. In other words, what is implied in the source language is stated clearly and explicitly in the target language. One of the reasons behind such differences and gaps between the number of tokens in Arabic and English is function words such as prepositions and whether they are written as individual words or attached to the next word. In Arabic, prepositions are sometimes written with the next word, but they are written in two or more words in English. For example, one Arabic word "بالع is translated into English as "in the world." Type/token ratio indicates the variety of the text's vocabulary; i.e., the highest the TTR, the more varied the text's vocabulary. Type tokens ratio of the Arabic corpus is 17,76, while it is 4,86 in the English corpus. This has also been reflected in the Standardized TTR since the number of the corpora is different as the ratio is 66.74 in the Arabic corpus and 42.16 in the English one.

\section{English Target Texts vs. English Source Texts}

In order to explore the differences between the target texts and source texts written in the same language, the researchers compared the English target corpus (the translation of the speeches that King Abdullah II delivered in Arabic) with a corpus of the speeches that the King delivered in English (English as a source corpus). To do so, Wordsmith 6 software is used, as Figures 5 and 6 show.

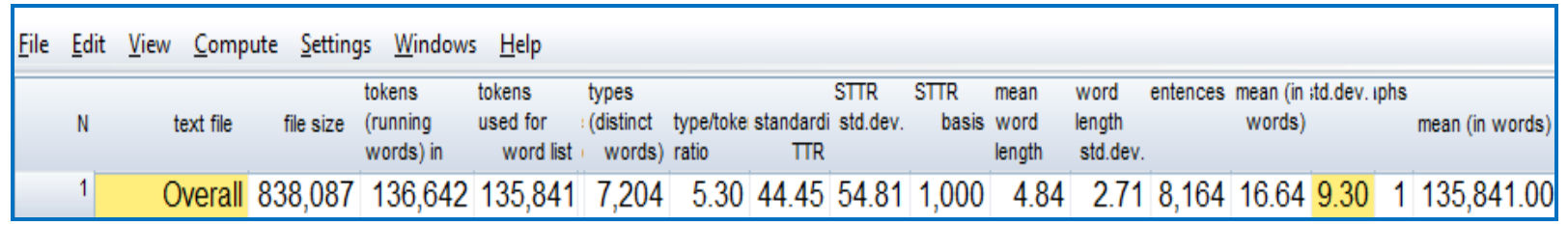

Figure 5. English source corpus statistics (WS6)

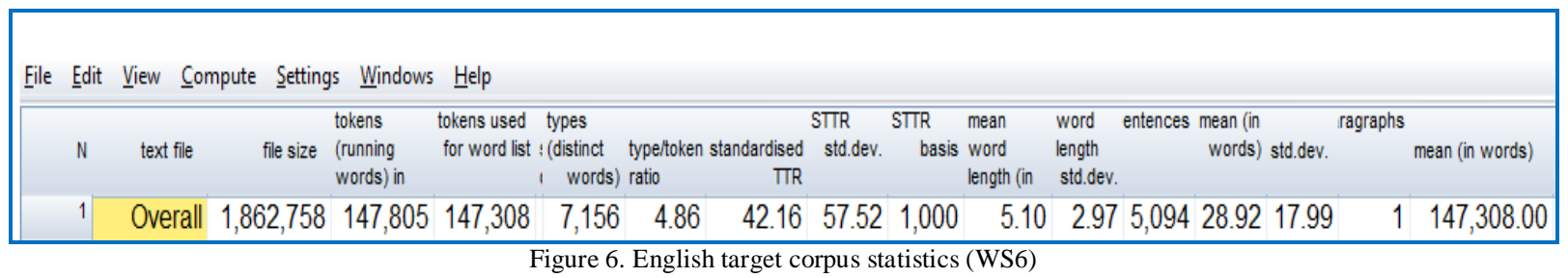

The information in figures 5 and 6 is summarized in Table 2 below.

TABLE 2

TYPES AND TOKENS OF ENGLISH TEXTS As TARGET AND SOURCE

\begin{tabular}{|c|c|c|}
\hline Criterion & English as Target & English as Source \\
\hline Tokens & 147,308 & 136,642 \\
\hline Types & 7,156 & 7,204 \\
\hline Type tokens ratio & 4.86 & 5.30 \\
\hline Standardized TTR & 42.16 & 44.54 \\
\hline
\end{tabular}

Table 2 shows that the number of types, TTR, and standardized TTR of the English target corpus are close to their counterparts in the English source corpus. This could be because the translators in the Royal Court are influenced by the linguistic style of King Abdullah II; i.e., they choose the same words that King Abdullah II uses in the speeches he delivers in English. This could also be because they translate all speeches of King Abdullah II from English into Arabic and English into Arabic.

\section{B. Keyword Analysis}

In keyword analysis, the researchers compared the corpus under investigation with the ArTenTen corpus that is available in Sketch Engine (Figure 7). It is an Arabic corpus that consists of a collection of texts extracted from the internet. It is a part of the "ArTenTen corpus family," which is a collection of online corpora that were created using the 
same techniques and have a target size of 10 billion words or more. TenTen corpora are available in more than 30 languages through Sketch Engine now. Keyword analysis enables researchers to identify the most salient words in the corpus under study when compared to a huge reference corpus. In the case of the current study, the keywords show the words that King Abdullah II frequently and saliently uses in his speeches. These can be cultural and are related to the Jordanian context. These might pose some difficulties and challenges to the translators rendering texts from Arabic into English.

\begin{tabular}{|c|c|c|c|c|c|c|c|c|c|c|}
\hline 1 & حضرات & $\cdots$ & العبث 11 & $\cdots$ & حرصنا 21 & $\cdots$ & الاردنيين 31 & $\cdots$ & فيسر 41 & $\cdots$ \\
\hline 2 & لن & $\cdots$ & الاردنيات 12 & $\cdots$ & اتوجه 22 & $\cdots$ & ليسرني 32 & $\cdots$ & لزملائك 42 & $\cdots$ \\
\hline 3 & لم & $\cdots$ & فيسرني 13 & $\cdots$ & اشقائ 23 & $\cdots$ & الافخم 33 & $\cdots$ & نشامى 43 & $\cdots$ \\
\hline 4 & بن & $\cdots$ & فرص 14 & $\cdots$ & اردن 24 & $\cdots$ & اعهد 34 & $\cdots$ & تكافؤ 44 & $\cdots$ \\
\hline 6 & مقدمت & $\cdots$ & زملائك 16 & $\cdots$ & نفتتح 26 & $\cdots$ & لو 36 & $\cdots$ & نؤكد 46 & $\cdots$ \\
\hline 7 & وفق & $\cdots$ & اعتزازنا 17 & $\cdots$ & يوفقنا 27 & $\cdots$ & الاشقاء 37 & $\cdots$ & فاعلة 47 & $\cdots$ \\
\hline 8 & النشامى & $\cdots$ & اعتزازي 18 & $\cdots$ & بك 28 & $\cdots$ & فيك 38 & $\cdots$ & زملاؤك 48 & $\cdots$ \\
\hline 9 & عزيزنا & $\cdots$ & الاعتزاز 19 & $\cdots$ & وسائر 20 & $\cdots$ & بدران 39 & $\cdots$ & واردنية 49 & $\cdots$ \\
\hline
\end{tabular}

Figure 7. A screenshot of the keywords in the Arabic corpus under study

Figure 7 shows the words that are the most salient and frequent in the Arabic corpus when compared to a huge reference corpus. It can be observed that some words that are context-based, i.e., related to the Jordanian culture, such

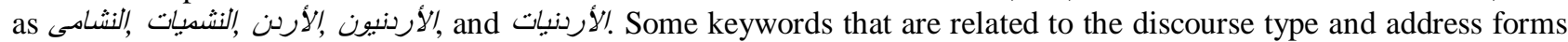

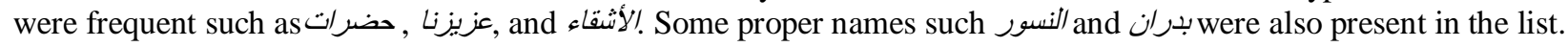

\section{Translating Culture-Bound Expressions from Arabic into English}

In this section, the researchers discuss the translation of some culture-bound expressions, such as the address forms mentioned in the keyword list, the challenges that might arise when translating them, and the strategies that the translators resorted to when doing so.

1. الأخت الأخ

In this part, the researchers discuss how the Arabic words " English in different contexts (Figure 8).

\begin{tabular}{|c|c|c|}
\hline 1 & 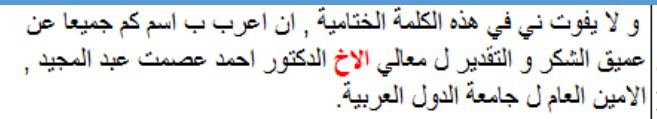 & $\begin{array}{l}\text { On behalf of all of you, I would like to express our great } \\
\text { appreciation to His Excellency Dr Ahmed Esmat Abdul } \\
\text { Maguid, the secretary general of the League of Arab States }\end{array}$ \\
\hline 2 & |تزيزنا دولة الاخ فيصل الفايز حفظه الله & Your Excellency Faisal Fayez \\
\hline 3 & رحم الله الحسين الاب و الاخ و القائد و الانسان. & $\begin{array}{l}\text { May God have mercy on the King, the father, the brother, the } \\
\text { commander and the man. }\end{array}$ \\
\hline 4 & 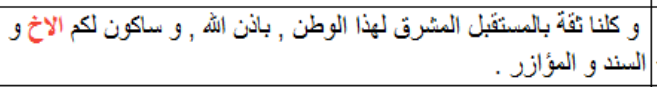 & $\begin{array}{l}\text { We have faith that a bright future is awaiting this country.God } \\
\text { willing, I will be to you a brother and a supporter. }\end{array}$ \\
\hline 5 & | و استّ عب الجميع , بروح الاب او الاخ الكبير. ال & and to accept everybody in a fatherly spirit \\
\hline 6 & الوطني مارجوه من كل اخ و اخت من كم هو المبادرة الى الفيام ب واجب ه & $\begin{array}{l}\text { We call upon each brother and sister to take the lead and } \\
\text { perform a national duty, }\end{array}$ \\
\hline 7 & |حيبكم , و احبي كل اخ و اخت في هذا الوطن العزيز & I salute you and salute each brother and sister in this dear natior \\
\hline
\end{tabular}

The Arabic words الأخت sister are used in the Muslim and Arab cultures as address forms showing intimacy. In such contexts, they are not used as kinship terms but to refer to members belonging to the same group, which could be social, religious, among others. This stems from Qur'anic verses and Prophet Mohammad's PBUH

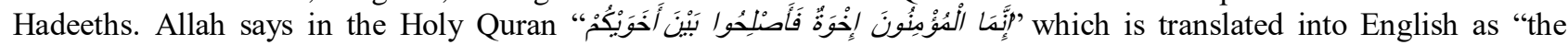
believers are but brothers, so make settlement between your brothers" (verse 49:10). This is common in the Arab culture where some people may call old women "ليهة" which means "my mother" though she is not their real mother.

Such forms of address are not present in some cultures, such as the English one, and this might create some problems

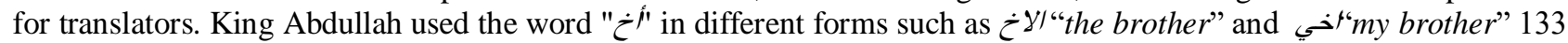
times, and خsister" 6 times.

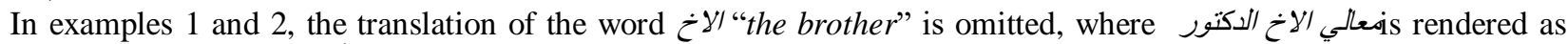
"His excellency Dr." and عزيزنا دولة الأخ is translated as "your excellency." In example 2, not only the word $\dot{\gamma}^{\gamma / b r o t h e r}$ is 
deleted, but also reflect respect and intimacy, and because the other words in the sentences reflected such respect such as which both mean "excellency." In example 3, the word الخ was translated literally in the context of talking about the

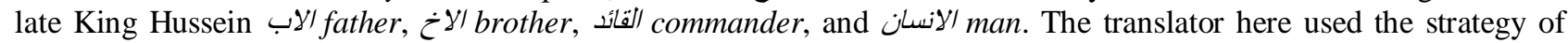
addition, where he added the word "the King," although it is not in the source text.

Similarly, in Example 4, the word $\dot{\chi}^{\gamma /}$ is also rendered as a brother. In the same example, the translator used the

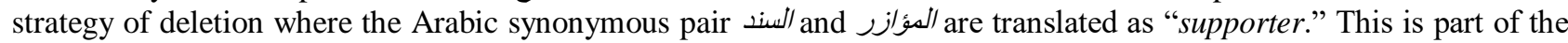
Arabic rhetoric, where the idea is emphasized by using some synonymous words such as النائي, which are translated as remote. In Example 5, روح الاب او الاخخ الكبير which literally means the fatherly and brotherly soul is rendered as "fatherly spirit." Hence, the strategy used here is deletion, most likely because the fatherly spirit is more than the brotherly one. In examples 6 and 7, the words $\dot{\gamma}$ /and $ت$ خ/are rendered as brother and sister.

2. اخوان

The Arabic word "خوان" "brothers" occurred in the speeches of King Abdullah II several times, especially when he code-switched from MSA into colloquial Arabic. In this section, the researchers analyze how it is rendered in English (Figure 9).

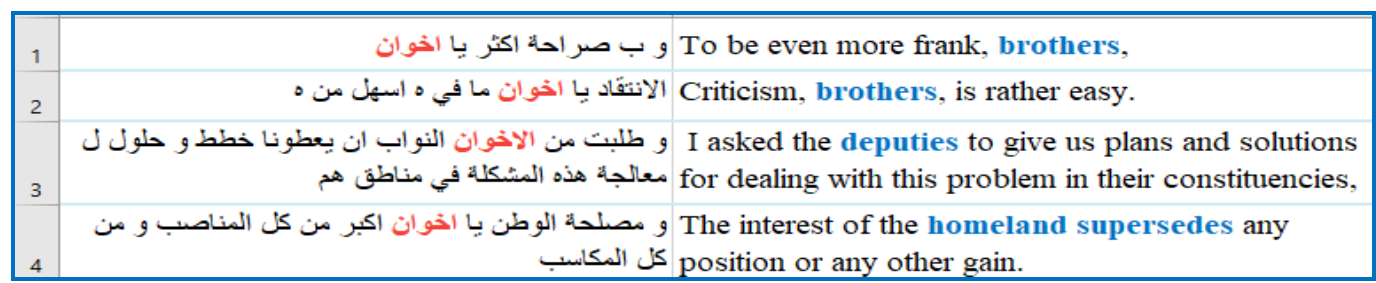

Figure 9. A screenshot of the Arabic word "اخوان" with the translation

The Arabic word "اخوان "brothers" has many indications and is used in different contexts in the Arab culture, but mainly as a form of address. In the speeches of King Abdullah, the word is used as part of جماعة الاخوان which refers to a political party, namely "Muslims brotherhood." In this section, the researchers examine the use of the word as a form of address, showing closeness and familiarity between community members. For example, in colloquial Arabic and informal situations, people frequently use "با اخوي "my brother" to show intimacy. In such a context, it does not necessarily mean that the person is addressing hisher real brother. King Abdullah II used this word when addressing Jordanian using the colloquial Jordanian variety of Arabic. This may cause a challenge to the translators because they need to explore the entire context to determine the intended meaning accurately and to select the true equivalent to convey the different aspects of the word. In examples (1) and (2), the translator decided to be faithful to the source language and rendered the investigated word as "brothers" which is the literal meaning of the Arabic word " In example (3), King Abdullah II was talking about deputies, and he called them " "اخوان." "brothers deputies." The translator rendered the examined word as "deputies" which means that the Arabic word"نوان" is omitted. So, the translation strategy of 'omission' is used here, as including it may sound redundant and not commonly used in western culture. In example (4), King Abdullah II was addressing the Jordanian people and used the word to show closeness towards them. In the Arab culture, the use of address forms may indicate familiarity in some situations and respect in others. For example, people may use words like uncle and خاعم aunt to address older men and women to show respect, and they may use $\dot{C}^{\prime}$ brother and خت when talking to males and females of similar age to show familiarity. In the translation of the incidents of خوان/in the speeches of King Abdullah, literal translation approach was sometimes followed, while in some other occasions, the word was left out and omitted.

3. الثقبق و الثقبقة

In this section, the researchers examine the Arabic words "الثقيق" "and" "الشقيقة "brother and sister" and how translators rendered them into English (Figure 10). 


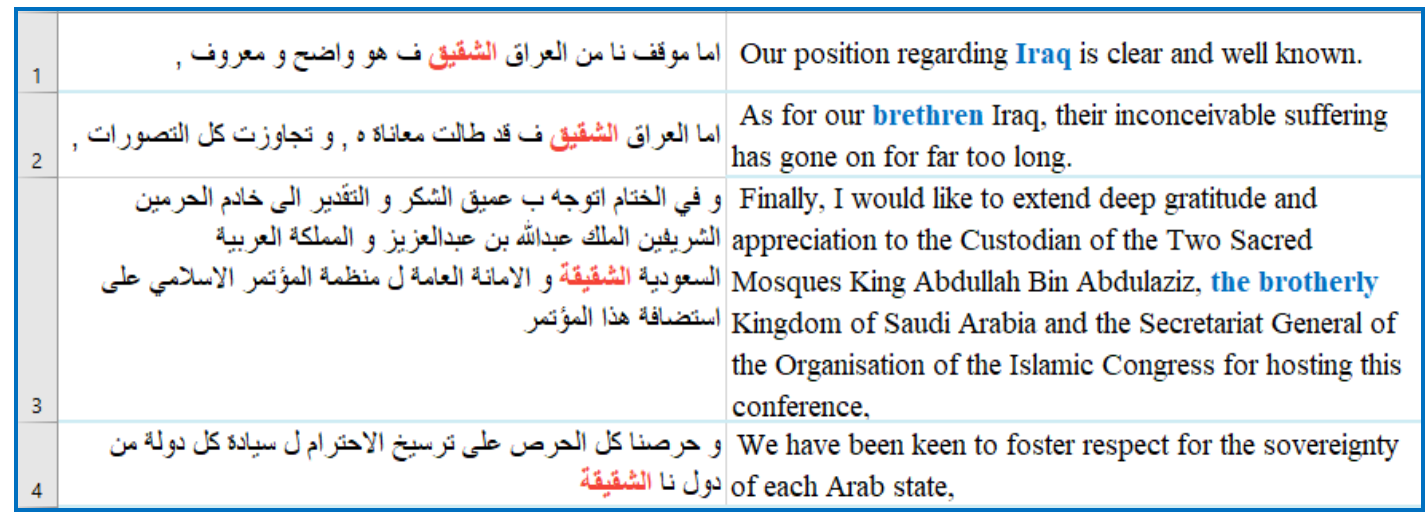

Figure 10. A screenshot of the Arabic word "الثققيقة" and "الثققيق

The words "الثقيق" and "الثقيقة" are used in Arabic to refer to brothers and sisters from the same mother and father; however, they are sometimes used figuratively to show intimacy. For example, if a person is talking about some other countries that share the same language, religion, heritage or tradition, he/she may use " الشققية " to indicate the commonalities. King Abdullah II used these words to describe Arab and Muslim countries that have good relations with Jordan and to show the strong connections between Jordan and Arab countries. In example (1), the interpreter translated the Arabic phrase "العراق الثقيق" into English as "Iraq." This means that in this incidence, the translation strategy of omission. Although the overall meaning of the phrase is not affected, it would be recommended to keep such words in the translation to convey some aspects of meanings that can strengthen relations between countries. In example (2), the translator rendered the investigated word as "brethren," which is a formal plural form of the word "brother" that is frequently used in religious situations. The term may also be used to describe any group of people with strong social ties. The researchers believe that the translator's choice gives a precise meaning that fits the context. In example (3), King Abdullah used the word to describe the Kingdom of Saudi Arabia, and the interpreters translated it into English as "brotherly," which is an adjective used to indicate fraternal relations with others. In example (4), the translator deleted

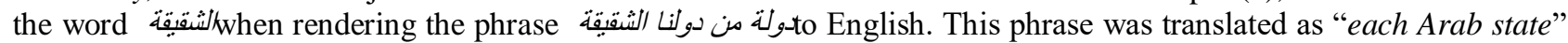
although the source text does not have the word "Arab." Accordingly, the translator sued the strategy of addition by adding the word "Arab" and "deletion" by omitting the word الثقيقة.

4. النشامى

In this part, some incidents of the Arabic word " لنشامى and its English counterparts are examined to check the strategies that the translators used to render it into English (Figure 11).

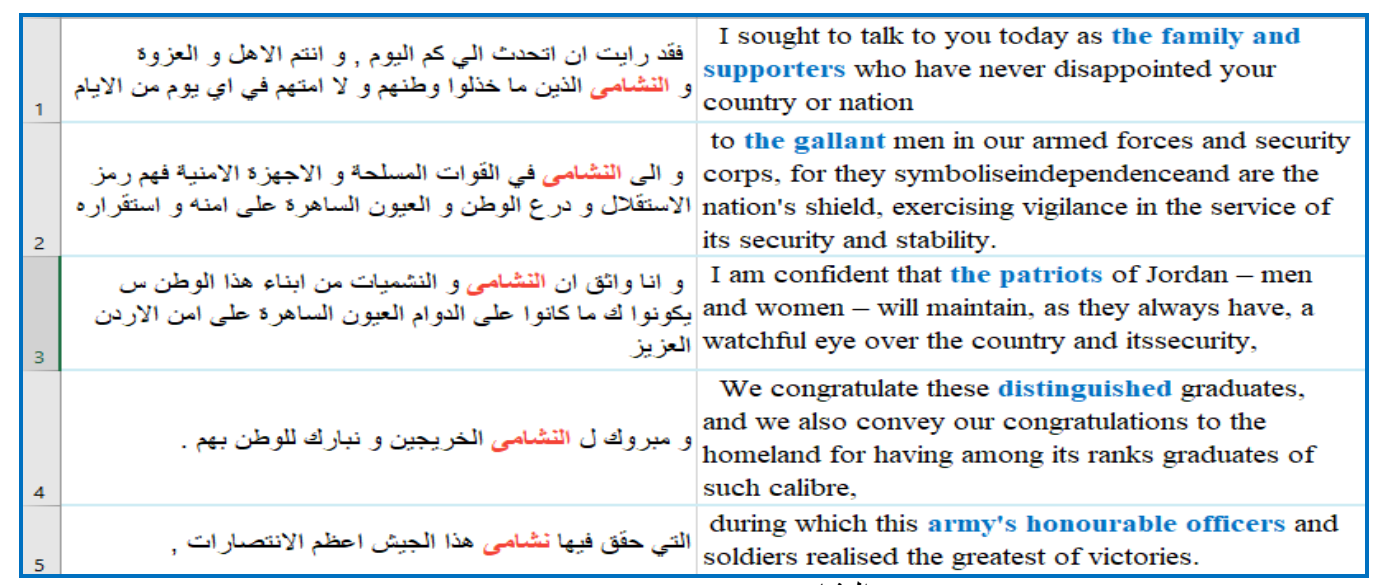

Figure 11. A screenshot of the Arabic word "النشامى" with the translation

The Arabic word "النشامى" is not a Modern Standard Arabic word, but these days it has become popular and is used in official speeches, especially in the Jordanian context. The Arabic word النشامى was used in the past to characterize Jordanian Bedouin people, who are known for their chivalry. The word is used these days to describe Jordanian people in general. In some cases, the examined word is used to refer to Jordanian people, students, and soldiers, to mention a few. An example of using this term is the phrase "منتخب النشامى "which literally means "The team of Nashama" which is used to refer to "Jordanian football team." Such a description sounds natural and is understandable for Arabic people. In example (1), the translator rendered the Arabic phrase "الأهل و العزوة و النشامى as "the family and supporters," so the investigated word is deleted which means that the translators used the strategy of deletion. In example (2), the interpreter translated the examined word as "gallant men." The word "gallant" in Cambridge Dictionary means "showing no fear of dangerous or difficult things." In example (3), the investigated word 
is translated into English as "patriots," which is a word used to describe a person who belongs and protects hislher country. So, the translation strategy used in this example is substitution, where the translator substituted the word with a more general one. In example (4), King Abdullah II congratulated the graduates and described them as النشامى to indicate their distinction. The translators rendered the investigated word as "distinguished," which doesn't give the actual meaning of the Arabic word. In this example, the translators used the strategy of substitution to give the intended meaning. In example (5), the interpreters translated the Arabic phrase is "نشامى هذا الجيث" which means "the chivalrous soldiers of this army" as "army's honorable officers." It is noticed that the Arabic word "شامى" is replaced by "officers" which means that the translators used the strategy of substitution.

\section{CONCLUSION}

Based on the analysis above, the translation strategies that were mainly resorted to by the translators and interpreters are omission, addition, transliteration, explicitation, and substitution. Deletion is defined as omitting some elements in the sentence which may cause repetition without affecting the intended meaning said by the speaker. This is in line with Baker (2018), who stated that deletion is the omission of some vocabulary to fit the audience's grammatical and semantic knowledge. Baker (2018) argued that this strategy may sound rather extreme, but it should not affect the meaning when a word or expression is deleted in some contexts. Translators and interpreters can omit some words or expressions if the meaning conveyed by these items is not vital. This may help readers or text receivers to easily understand the message without being distracted by lengthy explanations (Baker, 2018). In this study, the researchers noticed that the Royal Court translators used the deletion strategy frequently in translating the Arabic speeches of King Abdullah II. In some cases, it is justified because some details might be important rhetorically in Arabic and redundant in English. It is recommended this strategy to avoid overly repetition in the translated text bearing in mind that repetition is not acceptable in some contexts. For example, the Arabic words "الخاخ "brother" and " "sister" are not important to render in the target text as they reflect respect and intimacy in the Arabic culture, and are not used in the English speaking countries.

The researchers noticed that the Royal Court's translators used the addition and explicitation strategies in translating some of the culture-bound expressions in the Arabic speeches of King Abdullah II. They tended to add information that is not found in the source text to clarify some unclear and ambiguous points to the target language reader. Such additions can bridge the cultural differences between the source language/culture and the target language/culture. In this study, the researchers noticed that the translators resorted to this strategy to make the process of text comprehension easier without exerting much effort.

Substitution strategy was also used frequently by the translators, especially if the source language words do not have a direct or accurate equivalent in the target language. For example, the Arabic word " was translated differently based on the context; one time as officers and another as graduates among others. Transliteration was sometimes used to render some words that have a cultural reference in the source text, and their English equivalents may not fully deliver the different senses associated with these words.

In this study, the researchers examined a specific type of data (royal speeches), in two languages (Arabic as a source language and English as a target language), within a certain period (1999 to 2015) and used translation theory and corpus linguistics as theoretical and empirical approaches to a limited number of research questions. As a result, there are various limitations of the current study. This study uses a 256,000-word Arabic-English parallel corpus of the speeches of King Abdullah II of Jordan from 1999 to 2015. Other researchers can enlarge the corpus by compiling more speeches of King Abdullah covering the period from 2016 to now. The researchers discussed the translation produced by Royal Court translators, and it was extracted from the website of King Abdullah II. Also, the speeches used for investigation are translated from Arabic into English. Future researchers can analyze the translation of any other translators and change the direction of translation by examining the Arabic translation of the speeches that King Abdullah delivered in English. Another limitation is related to the genre of the compiled texts. Further research can investigate other genres, such as literary texts. Such texts give the translators space to show their translation style. Unlike political texts, translators should be creative while translating literary texts such as novels, poetry, drama, and short stories.

This study can be helpful for translators and interpreters, especially those working on translating political texts. It is recommended that they pay more attention to the cultural aspects by getting acquainted with the source and target cultures. In addition, the corpus compiled in this study will be available upon request and can be used in translation classes or for training purposes.

\section{REFERENCES}

[1] Abdi, H., \& Satariyan, A. (2020). Translating Political Texts with and without the Defined Skopos: The Case of Iranian Translators. Journal of Language Translation, 10(1), 15-26.

[2] Afzali, K. (2013). The Translator's Agency and the Ideological Manipulation in Translation: the Case of Political Texts in Translation Classrooms in Iran. International Journal of English Language Translation Studies, 1(2), 196-208.

[3] Al-Abbas, L. S., \& Haider, A. S. (2020). The representation of homosexuals in Arabic-language news outlets. Equality, Diversity Inclusion: An International Journal. doi:https://doi.org/10.1108/edi-05-2020-0130 
[4] Al-Hamad, M. Q. (2013). Socio-Political Constraints on Translating Verbal and Non-Verbal Texts. Journal of Arts Humanities, 2(1), 93-102.

[5] Al-Hammad, M. (1999). Political discourse analysis: An Arabic - English contrastive case stud. (M.A. Thesis), Yarmouk University, Jordan.

[6] Al-Sayed Ahmad, A., Hammo, B., \& Yagi, S. (2017). English-Arabic Political Parallel Corpus: Construction, Analysis and a Case Study in Translation Strategies. Jordanian Journal of Computers Information Technology, 3(3), 157-171.

[7] Al-Zu'bi, I. (2000). Difficulties that MA students encounter in translating political expressions from his majesty king Abdullah's our last best chance. (M.A. Thesis ), Middle East University, Jordan.

[8] Alansary, S., Nagi, M., \& Adly, N. (2007). Building an international corpus of Arabic (ICA): Progress of compilation stage. Paper presented at the 7th international conference on language engineering, Cairo, Egypt.

[9] Ayasrah, M. T. (2017). Problems Encountered by MA Students in Translating Metaphors in Political Speeches of King Abdullah II and their Adopted Strategies. (M.A. Thesis), Middle East University, Jordan.

[10] Baker, M. (2018). In other words: A coursebook on translation. London: Routledge.

[11] Baker, P. (2004). Querying Keywords: Questions of Difference, Frequency, and Sense in Keywords Analysis. Journal of English Linguistics, 32(4), 346-359. doi:10.1177/0075424204269894

[12] Bánhegyi, M. (2014). Translation and political discourse. Acta Universitatis Sapientiae, Philologica, 6(2), 139-158.

[13] Davaninezhad, F. K. (2016). Supplementary practices and decreasing translation problems in translating political English news texts into Persian. Theory Practice in Language Studies, 6(1), 184-193.

[14] Dazdarevic, S., Zoranic, A., \& Fijuljanin, F. (2015). Benefits of Corpus-based Approach to Language Teaching. Balkan Distance Education Network-BADEN Newsletter Year III, 3(7), 1-4.

[15] Debbas, M., \& Haider, A. S. (2020). Overcoming Cultural Constraints in Translating English Series: A Case Study of Subtitling Family Guy into Arabic. 3L: Language, Linguistics, Literature®, 26(1), 1-17. doi: http://dx.doi.org/10.17576/3L2020-2601-01

[16] Haider, A. S. (2019a). The Representation of Al-Megrahi's Release in Arabic and English Newspapers in 2009 and 2010: A Corpus-assisted Discourse Study. Dirasat, Human Social Sciences, $46(1 \quad$ Supplement 2), $297-317$. doi:https://journals.ju.edu.jo/DirasatHum/article/download/15527/10121

[17] Haider, A. S. (2019b). Syrian-Lebanese Relations: A Corpus-based Critical Discourse Analysis of Bashar Al-Assad's Speeches and Interviews. Dirasat, Human Social Sciences, 46(4), 551-570.

[18] Haider, A. S., \& Hussein, R. F. (2020). Analysing headlines as a way of downsizing news corpora: Evidence from an ArabicEnglish comparable corpus of newspaper articles. Digital Scholarship in the Humanities, 35(4), 826-844. doi:https://doi.org/10.1093/llc/fqz074

[19] Haider, A. S., \& Olimy, S. (2019). The Representation of Laji'een (Refugees) and Muhajireen (Migrants) in the Headlines of Jordan News Agency (PETRA). International Journal for the Semiotics of Law-Revue internationale de Sémiotique juridique, 32, 155-186. doi:https://doi.org/10.1007/s11196-018-9550-4

[20] Hunston, S. (2002). Corpora in Applied Linguistics. Cambridge: Cambridge University Press.

[21] Kenny, D. A. (1999). Norms and creativity: lexis in translated text. (PhD), University of Manchester: UMIST, The UK.

[22] Kilgarriff, A., Baisa, V., Bušta, J., Jakubíček, M., Kovář, V., Michelfeit, J., Suchomel, V. (2014). The Sketch Engine: ten years on. Lexicography, 1(1), 7-36.

[23] McEnery, T., \& Wilson, A. (2001). Corpus linguistics. Edinburgh: Edinburgh University Press.

[24] Mehawesh, M. I. (2016). Figures of Speech in the Translation of King Abdullah II Political Speeches. Journal of Literature, Languages and Linguistics, 18, 55-61.

[25] Munday, J. (1998). A computer-assisted approach to the analysis of translation shifts. Meta: journal des traducteurs/Meta: Translators' Journal, 43(4), 542-556.

[26] Munday, J. (2007). Translation and ideology: A textual approach. The translator, 13(2), 195-217.

[27] Newmark, P. (1988). A textbook of translation (Vol. 66). New York: Prentice hall

[28] Nida, E. A., \& Taber, C. R. (1982). The theory and practice of translation (Vol. 8). Leiden: Brill Archive.

[29] Sárosi-Márdirosz, K. (2014). Problems related to the translation of political texts. Acta Universitatis Sapientiae, Philologica, 6(2), 159-180.

[30] Schäffner, C. (2004). Political discourse analysis from the point of view of translation studies. Journal of language politics, $3(1), 117-150$.

[31] Schäffner, C. (2008). 'The prime minister said...': voices in translated political texts. Synaps, 22, 3-25.

[32] Scott, M. (1999). WordSmith Tools (Software). Oxford University Press: Oxford.

[33] Scott, M. (2012). WordSmith tools version 6. Stroud: Lexical Analysis Software.

[34] Shunnaq, A. (2000). Arabic-English translation of political speeches. Perspectives: Studies in Translatology, 8(3), $207-228$.

[35] Taylor, C. (2008). What is corpus linguistics? What the data says. ICAME journal, 32, 179-200.

[36] Toury, G. (1995). The nature and role of norms in translation. Descriptive translation studies and beyond, 4, 53-69.

[37] Vinay, J.-P., \& Darbelnet, J. (1995). Comparative stylistics of French and English: A methodology for translation (Vol. 11). Netherlands: John Benjamins Publishing.

Leen Al-Khalafat received her Master in Audiovisual ad Mass Media Translation from the Applied Science Private University, Amman, Jordan. Her main areas of interest include corpus linguistics, pragmatics, and translation studies.

Ahmad S Haider (Corresponding) is an associate professor in the Department of English Language and Translation at the Applied Science Private University, Amman, Jordan. He received his Ph.D. in Linguistics from the University of Canterbury/ New 
Zealand. His current research focuses on how political events are socially, discursively, and linguistically represented in media combining Corpus Linguistics and (Critical) Discourse Analysis. His main areas of interest include corpus linguistics, discourse analysis, pragmatics, and translation studies. Dr. Haider has built different large Arabic and English corpora. He professionally masters different Corpus Linguistic software packages. http://orcid.org/0000-0002-7763-201X 